This item was submitted to Loughborough's Research Repository by the author.

Items in Figshare are protected by copyright, with all rights reserved, unless otherwise indicated.

\title{
Exploitation of GFP fusion proteins and stress avoidance as a generic strategy for the production of high quality recombinant proteins
}

PLEASE CITE THE PUBLISHED VERSION

http://www3.interscience.wiley.com/journal/118512081/home

\section{PUBLISHER}

(C) Federation of European Microbiological Societies / Blackwell Publishing Ltd

\section{VERSION}

SMUR (Submitted Manuscript Under Review)

\section{LICENCE}

CC BY-NC-ND 4.0

\section{REPOSITORY RECORD}

Sevastsyanovich, Yanina, Sara Alfasi, Tim Overton, Richard Hall, Jo Jones, Christopher J. Hewitt, and Jeff Cole. 2010. "Exploitation of GFP Fusion Proteins and Stress Avoidance as a Generic Strategy for the Production of High Quality Recombinant Proteins". figshare. https://hdl.handle.net/2134/5759. 
This item was submitted to Loughborough's Institutional Repository (https://dspace.lboro.ac.uk/) by the author and is made available under the following Creative Commons Licence conditions.

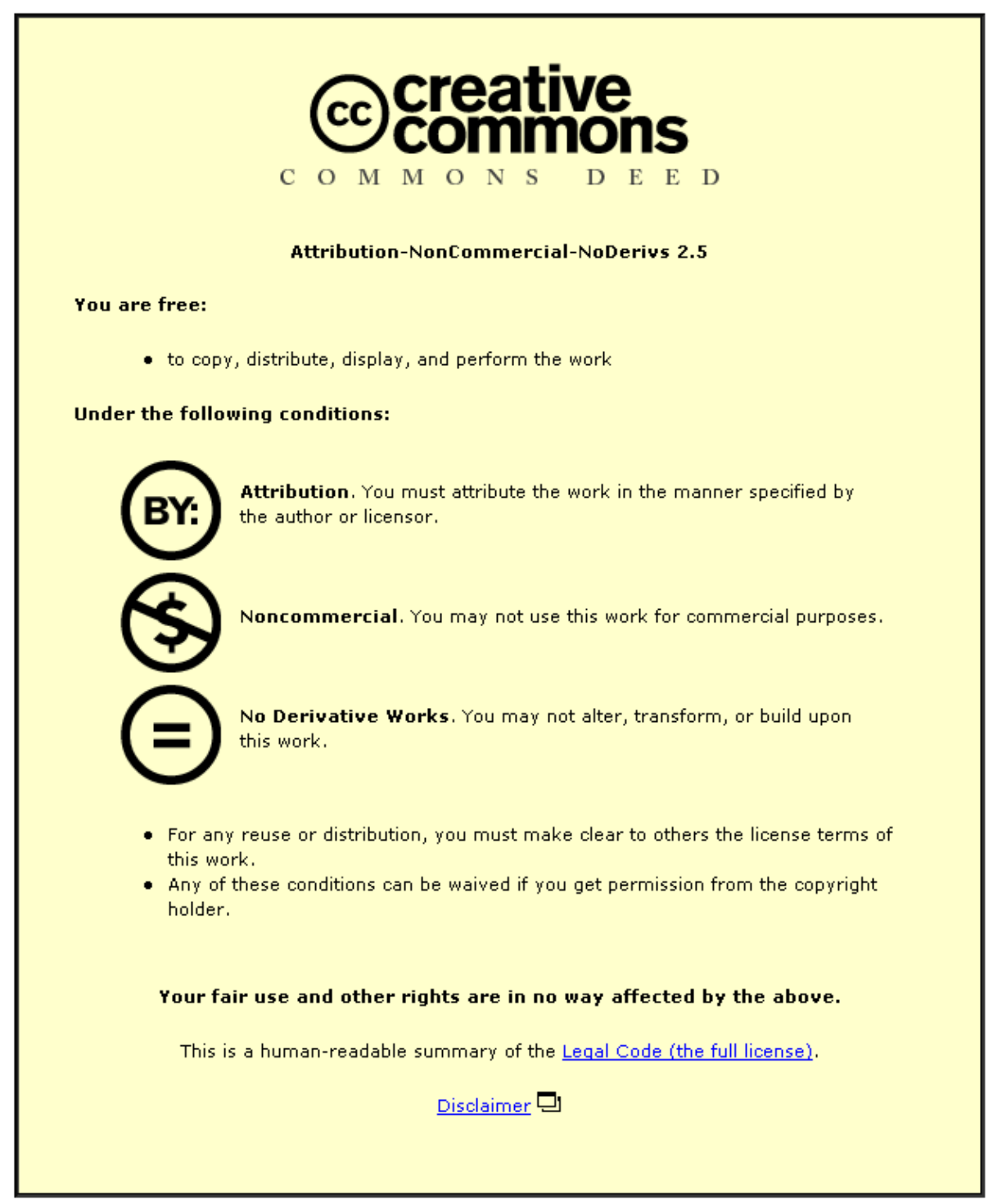

For the full text of this licence, please go to: http://creativecommons.org/licenses/by-nc-nd/2.5/ 


\section{MICROBIOLOGY LETTERS

http://mc.manuscriptcentral.com/fems

\section{Exploitation of GFP fusion proteins and stress avoidance as a generic strategy for the production of high quality recombinant proteins}

\begin{tabular}{|r|l|}
\hline Journal: & FEMS Microbiology Letters \\
\hline Manuscript ID: & draft \\
\hline Manuscript Type: & Research Letter \\
\hline Complete List of Authors: & $\begin{array}{l}\text { Sevastsyanovich, Yanina; University of Birmingham, School of } \\
\text { Biosciences } \\
\text { Alfasi, Sara; University of Birmingham, School of Biosciences } \\
\text { Overton, Tim; University of Birmingham, School of Chemical } \\
\text { Engineering } \\
\text { Hall, Richard; GlaxoSmithKline Research and Development } \\
\text { Jones, Jo; GlaxoSmithKline Research and Development } \\
\text { Hewitt, Christopher; Loughborough University, Chemical } \\
\text { Engineering } \\
\text { Cole, Jeff; University of Birmingham, School of Biosciences; None }\end{array}$ \\
\hline Keywords: & $\begin{array}{l}\text { Recombinant protein production, inclusion bodies, gonococcal I } \\
\text { cytochrome c2, heat shock, general stress response, green } \\
\text { fluorescent protein, flow cytometry }\end{array}$ \\
\hline
\end{tabular}

\section{今scholarONE \\ Manuscript Central}


1 Exploitation of GFP fusion proteins and stress avoidance as a generic strategy for the

2 production of high quality recombinant proteins

3

4 Yanina Sevastsyanovich $^{1 \dagger}$, Sara Alfasi ${ }^{1 \dagger}$, Tim Overton ${ }^{2}$, Richard Hall ${ }^{3}$, Jo Jones ${ }^{3}$, Christopher $5 \quad$ Hewitt $^{4} \&$ Jeff Cole ${ }^{1 *}$

6

$7{ }^{1}$ School of Biosciences and ${ }^{2}$ School of Chemical Engineering, University of Birmingham,

8 Birmingham, UK; ${ }^{3}$ GlaxoSmithKline Research and Development, Gunnels Wood Road,

9 Stevenage, Herts, UK; and ${ }^{4}$ Chemical Engineering, University of Loughborough,

10 Loughborough, Leicestershire, UK.

$12{ }^{*}$ Correspondence: Jeff Cole, School of Biosciences, University of Birmingham, Birmingham 13 B15 2TT, UK. Tel.: +44 121414 5440, fax: +44 121414 5495, email: j.a.cole@bham.ac.uk

\section{Keywords}

16

17 Recombinant protein production; inclusion bodies; gonococcal 1 cytochrome $c_{2}$; heat shock;

18 general stress response; green fluorescent protein; flow cytometry

$20{ }^{\dagger}$ The first two authors contributed equally to this work. 


\section{Abstract}

23

24

A C-terminal GFP fusion to a model target protein, Escherichia coli CheY, was exploited both as a reporter of the accumulation of soluble recombinant protein, and to develop a generic approach to optimise protein yields. The rapid accumulation of CheY::GFP expressed from a pET20 vector under the control of an IPTG-inducible T7 RNA polymerase resulted not only in the well-documented growth arrest, but also loss of culturability and overgrowth of the productive population by plasmid deficient bacteria. The fluorescence of cultures due to the accumulation of CheY::GFP were optimised by using very low concentrations of IPTG that avoid growth arrest and loss of culturability post-induction. Optimal product yields were obtained with $8 \mu \mathrm{M}$ IPTG, a concentration so low that insufficient T7 RNA polymerase accumulated to be detectable by Western blot analysis. The improved protocol was shown to be suitable for process scale-up and intensification. It is also applicable to the accumulation of an untagged heterologous protein, cytochrome $c_{2}$ from Neisseria gonorrhoeae, that requires both secretion and extensive post-translational modification.

\section{Introduction}

Many biopharmaceutical projects require the production of recombinant proteins in heterologous bacterial hosts. When the protein itself is the end product, the requirement for rapid, bulk production in high yield drives the design of a successful process. At the other extreme, high quality protein is often required as the starting point for NMR or X-ray crystallographic structure determination, or for understanding the biology underlying a process. Quality rather than quantity or production intensity now becomes the overriding requirement. 
The ability to express almost any gene at a controllable level makes bacterial hosts and plasmids attractive vehicles for generating the desired product. Despite the availability of a plethora of expression systems, detailed knowledge of the genome sequences, molecular biology, physiology and biochemistry of a range of production hosts, many proteins remain difficult to produce at the scale or quality required. Frequently encountered problems include the deposition of the target protein in insoluble inclusion bodies (Villaverde \& Carrio, 2003), lysis of the production host due to the physiological stress induced by high-level synthesis of mRNA and the heterologous protein (Gill et al., 2000), and accumulation of multiple fragments of the target protein due to proteolysis (Dürrschmid et al., 2008).

The primary cause of many of the problems is the accumulation of incorrectly folded intermediate forms of the target protein. In bacteria like E. coli, this is a signal that induces not only the general stress response, but also other overlapping responses (Hoffmann \& Rinas, 2004; Gasser et al., 2008). If the correct folding of the target protein is the only problem to be solved, over-expression of chaperones might be sufficient to achieve success, for example, by pre-inducing the RNA polymerase RpoH regulon with a heat shock (Hoffmann \& Rinas, 2004), or the co-expression of groEL, dnaK or other chaperone genes (Nishihara et al., 1998; Chen et al., 2003; Schrodel et al., 2005; Mitsuda \& Iwasahi, 2006; Hu et al., 2007; de Marco, 2007). More often, however, failure is due directly to the consequences of the induction of the RpoH-dependent stress response (Vera et al., 2006; Rabhi-Essafi et al., 2007; Lin et al., 2008) especially the disaggregation complex in which DnaK, ClpB and IbpAB remove aggregated recombinant proteins for proteolysis (reviewed by Gasser et al., 2008). We now report results of experiments designed to analyse the physiological cause of failure to accumulate a soluble, cytoplasmic recombinant protein, and the design of a generic strategy to minimise the problem. Although our main model system is based upon the production of the E. coli chemotaxis protein CheY, fused with a C-terminal 
72 green fluorescent protein (GFP) tag, we show that a similar approach can be used to 73 accumulate an untagged recombinant protein that requires both secretion to the periplasm and 74 extensive post-translational modification.

\section{Materials and methods}

\section{E. coli strain and plasmids}

The Escherichia coli strains BL21(DE3)* (Invitrogen) and its derivatives, C41 and C43

(Miroux \& Walker, 1996) were used for recombinant protein expression work. E. coli strain

JM109 (Promega) was used to clone the cytochrome $c_{2}$ gene from Neisseria gonorrhoeae.

The over-expression of CheY::GFP fusion gene or the gonococcal gene encoding cytochrome $83 c_{2}$ from Neisseria gonorrhoeae was induced from the IPTG-inducible T7 promoter of the expression vectors pET20bhc-CheY::GFP and pET20bhc- $c_{2}$, respectively, both of which are derived from a slightly modified version of pET20b (Novagen; Waldo et al., 1999; Jones et al., 2004).

The $c c c A$ gene (accession number NGO0292) encoding cytochrome $c_{2}$ was amplified

88 from Neisseria gonorrhoeae strain F62 genomic DNA using primers

CATAGGGATCCTTAGAAAGGTTTGATTTG (incorporating NdeI and BamHI restriction

91 sites, respectively, shown in bold type) and PCR SuperMix High Fidelity (Invitrogen)

92 according to manufacturer's instructions. The thermal cycling profile included 1 cycle at $94^{\circ} \mathrm{C}$ 93 for $3 \mathrm{~min}$., $10 \mathrm{x}\left(94^{\circ} \mathrm{C}\right.$ for $30 \mathrm{~s}, 40^{\circ} \mathrm{C}$ for $30 \mathrm{~s}, 68^{\circ} \mathrm{C}$ for $\left.1 \mathrm{~min}.\right), 27 \mathrm{x}\left(94^{\circ} \mathrm{C}\right.$ for $30 \mathrm{~s}, 55^{\circ} \mathrm{C}$ for 30 $94 \mathrm{~s}, 68^{\circ} \mathrm{C}$ for $1 \mathrm{~min}$.) and $1 \times 68^{\circ} \mathrm{C}$ for $10 \mathrm{~min}$. The $465 \mathrm{bp}$ PCR product was cloned into pGEM95 T Easy (Promega), sequenced and the $c c c A$ fragment was transferred as an NdeI - Bam HI 96 fragment into pET20bhc vector digested with NdeI and BamHI. In experiments to accumulate 
97 mature cytochrome $c_{2}$ from $N$. gonorrhoeae, bacteria were co-transformed with the second 98 plasmid, pST2, that encodes the $E$. coli cytochrome $c$ maturation proteins, CcmA-H (Turner 99 et al., 2003).

\section{Growth conditions for the standard protocol}

102 Bacteria were grown aerobically in $100 \mathrm{~mL}$ shake flasks with $20 \mathrm{~mL}$ working volume or in a $1033.6 \mathrm{~L}$ fermenter (Infors) with a $2.8 \mathrm{~L}$ working volume of Luria-Bertani medium supplemented 104 with $2 \%(\mathrm{w} / \mathrm{v})$ glucose and $100 \mu \mathrm{g} \mathrm{mL}^{-1}$ carbenicillin for plasmid maintenance. The shake 105 flasks were set up in duplicates or triplicates per culture condition. In fermentations, aeration 106 was maintained at $1 \mathrm{vvm}$ and a stirring speed of $700 \mathrm{rpm}$. The $\mathrm{pH}$ was controlled at 6.3 by the 107 automated addition of 5\% (v/v) $\mathrm{HCl}$ and $10 \%(\mathrm{v} / \mathrm{v}) \mathrm{NH}_{3}$ and $0.1 \%(\mathrm{v} / \mathrm{v})$ silicone antifoam was 108 added in the medium to prevent foaming of the culture during the late stages of the 109 fermentation. The medium was inoculated with $2 \%(\mathrm{v} / \mathrm{v})$ of seed culture grown aerobically at $11030^{\circ} \mathrm{C}$ for approximately 14 hours. Bacteria were grown at $37^{\circ} \mathrm{C}$ to an $\mathrm{OD}_{650}$ of approximately 1110.5 at which recombinant protein expression was induced with $0.5 \mathrm{mM}$ IPTG. Bacteria were 112 grown at $25^{\circ} \mathrm{C}$ thereafter to facilitate correct folding of the recombinant protein. Culture 113 samples were taken before induction and at various intervals up to 25 hours post-induction.

\section{Growth conditions for the improved protocol}

116 Bacteria were inoculated and grown in the same medium as that used for the standard 117 protocol. However, bacteria were grown aerobically at $25^{\circ} \mathrm{C}$ to an $\mathrm{OD}_{650}$ of approximately 0.5 118 at which point recombinant protein production was induced with $8 \mu \mathrm{M}$ IPTG. Bacterial 119 growth was continued at $25^{\circ} \mathrm{C}$ for up to 70 hours post-induction. 
122 E. coli $\mathrm{BL} 21 *(\mathrm{DE} 3)$ (Invitrogen) containing pET20bhc- $c_{2}$ and $\mathrm{pST} 2$ was used to produce

123 mature cytochrome $c_{2}$ in an anaerobic fermenter. The fermentation medium contained $50 \%$

124 Luria-Bertani broth, $40 \%$ E. coli sulphur-free minimal salts, $10 \mathrm{mM}$ TMAO, $10 \mathrm{mM}$ sodium

125 fumarate, $2 \%$ glucose, $0.1 \%$ silicone antifoam, $100 \mu \mathrm{g} \mathrm{mL} L^{-1}$ carbenicillin and $30 \mu \mathrm{g} \mathrm{mL}^{-1}$

126 chloramphenicol. The fermenter was inoculated with $4 \%$ of a seed culture that had been

127 grown for $16 \mathrm{~h}$ at $30^{\circ} \mathrm{C}$ with aeration. The culture in the fermenter was grown at $30^{\circ} \mathrm{C}$ at 100

$128 \mathrm{rpm}$ stirring speed without aeration; $\mathrm{pH}$ was controlled at 6.3 with $5 \% \mathrm{HCl}$ and $10 \%$

129 ammonia. Protein expression was induced by adding $10 \mu \mathrm{M}$ IPTG at $\mathrm{OD}_{650}$ of approximately

130 0.5. The bacterial culture samples were taken before induction and at various time points for 131 up to $24 \mathrm{~h}$ post-induction.

132

133 Plating and replica plating for plasmid retention

134 To test the effect of recombinant protein production on the culturability of the bacterial host,

135 serial dilutions of the bacterial culture were plated onto non-selective nutrient agar (Oxoid)

136 and incubated at $30^{\circ} \mathrm{C}$. The proportion of plasmid-bearing bacteria was estimated by replica

137 plating the resultant colonies on nutrient agar supplemented with carbenicillin $\left(100 \mu \mathrm{g} \mathrm{mL}^{-1}\right)$.

139 Analysis of recombinant protein accumulation by SDS-PAGE

140 Proteins were resolved by Tris/Tricine SDS-PAGE using a 15\% (w/v) polyacrylamide gel 141 (Sambrook et al., 1989) and stained with $0.2 \%(\mathrm{w} / \mathrm{v})$ Coomassie Blue. Total protein was analysed

142 from whole cell samples resuspended in $67 \mu \mathrm{L}$ of sample buffer per $\mathrm{OD}_{650}$ unit so that the biomass

143 per volume for all samples was the same. The samples were heated to $100^{\circ} \mathrm{C}$ for 10 minutes before

144 loading at the same volume. Recombinant protein yield was estimated by densitometry using the

145 Quantity one software (Bio-Rad). 
146 The yield of soluble and insoluble recombinant protein accumulated was determined from

147 fractionated bacterial samples. Bacterial cell pellets were resuspended in BugBuster lysis reagent

148 (67 $\mu \mathrm{L}$ of BugBuster per $\mathrm{OD}_{650}$ unit) (Novagen) and incubated at room temperature for 10 minutes

149 with gentle shaking. The soluble and insoluble cell fractions were separated by centrifugation at $15013,000 \mathrm{rpm}$ at $4^{\circ} \mathrm{C}$ for $20 \mathrm{~min}$. The separated fractions were resuspended in the same volume of 151 sample buffer as the volume of BugBuster used for lysis and boiled at $100^{\circ} \mathrm{C}$ for 10 minutes. To 152 ensure that the samples contain equal biomass, two volumes of the soluble and 1 volume of the 153 insoluble cell fractions were loaded and analysed by SDS-PAGE.

154 Proteins containing covalently attached heme were detected using heme-dependent 155 peroxidase activity (Thomas et al., 1976).

\section{Fluorescence determination}

158 Fluorescence of culture samples taken at various intervals throughout the experiment were

159 measured using a Perkin-Elmer fluorescence spectrophotometer model 203 at settings that 160 allowed accurate readings from a calibration curve. The accumulation of the soluble 161 CheY::GFP was detected using an excitation wavelength of $485 \mathrm{~nm}$ and an emission 162 wavelength of $509 \mathrm{~nm}$. The same culture diluted in phosphate buffered saline (PBS; 163 Sambrook et al., 1989) was used for optical density measurement and for fluorescence 164 measurement.

166 Flow cytometry

167 The proportion of green fluorescent bacteria overproducing the GFP-tagged recombinant protein in 168 the culture and their physiological state were analysed by flow cytometry (BD FACSAria II: 169 Becton, Dickinson \& Co.). Bacteria were diluted in PBS at a final concentration of $10^{5}-10^{6} \mathrm{~mL}^{-1}$ 170 and analysed at a data rate of 1000-2000 events $\sec ^{-1}$. An eighty-five $\mu \mathrm{m}$ nozzle was used for the 
171 analysis. The red fluorescent dye propidium iodide (PI, Sigma) was added to the samples to stain

172 dead bacteria. The PI stock solution was made up at $1 \mathrm{mg} \mathrm{mL}^{-1}$ in distilled water and used for

173 staining at the working concentration of $5 \mu \mathrm{g} \mathrm{mL}^{-1}$ (Hewitt et al., 1999). All solutions were passed

174 through $0.2 \mu \mathrm{m}$ filter immediately prior to use to remove particles. The backflush cleaning was

175 applied between samples to prevent cross-contamination. The sample was excited with a $488 \mathrm{~nm}$

176 solid state laser $(13 \mathrm{~mW})$. The software discriminator was set on the forward scatter to reduce

177 electronic and small particle noise. Forward and side scatter data were collected along with GFP

178 fluorescence (502LB, 530/30BP) and PI fluorescence (610LP, 616/23BP). For each experiment,

179100000 data points were collected and analysed using BD FACSDiva software (BD Biosciences).

180

181 Western blotting

182 For Western analysis, culture samples were resuspended in sample buffer as described above

183 (SDS-PAGE section) and loaded onto NuPAGE 4-12\% Bis-Tris gel (Invitrogen). The proteins

184 were transferred onto Hybond-ECL nitrocellulose membrane (Amersham) in the Xcell II blot

185 module (Invitrogen). The blots were incubated with T7 RNA polymerase antibodies

186 (Novagen) and then with peroxidase-conjugated anti-mouse $\operatorname{IgG}$ (Amersham) according to the

187 manufacturers' instructions. The blots were developed using EZ-ECL Chemiluminescence

188 detection kit (Biological Industries) according to the provided protocol.

189

190 Results

191

192 Standard protocol for CheY::GFP accumulation

193 Many laboratories use the commercially available pET plasmids to express a cloned gene in

194 an E. coli host under the control of T7 RNA polymerase that is both chromosomally encoded

195 and regulated by an IPTG-inducible promoter. This system was used in initial experiments to 
196 produce a $42 \mathrm{kDa}$ CheY::GFP fusion protein (Jones, 2007). It had been observed that, in

197 contrast to N-terminal GFP fusion proteins, optimisation of fermentation conditions for the 198 accumulation of a fluorescent recombinant protein with a carboxy-terminal GFP fusion 199 provides a good prediction of how to generate the correctly folded N-terminal target protein 200 without a fusion tag. Expression of the gene encoding CheY::GFP cloned into plasmid 201 pET20bhc-CheY::GFP was induced with $0.5 \mathrm{mM}$ IPTG at a low biomass density of $0.2 \mathrm{~g}$ dry 202 mass $\mathrm{L}^{-1}$, and the temperature was decreased from $37^{\circ} \mathrm{C}$ to $25^{\circ} \mathrm{C}$. Samples of the culture taken 203 before induction and at intervals for $24 \mathrm{~h}$ post-induction were analysed for growth, 204 fluorescence, plasmid retention, colony-forming ability, and the accumulation of recombinant 205 protein in both soluble and insoluble cell fractions.

206 The optical density of the culture increased only slowly soon after IPTG addition, but 207 growth resumed after a lag of between 10 to $14 \mathrm{~h}$ for up to $24 \mathrm{~h}$ post-induction. Plating of 208 serial dilutions of samples taken 2 to $4 \mathrm{~h}$ post-induction revealed that only about $1 \%$ of the 209 bacteria were able to form colonies on non-selective agar, but high plating efficiency was 210 restored after $24 \mathrm{~h}$ (Fig. 1A). In contrast to colonies from samples taken before induction that 211 were pale green due to leaky expression of the recombinant protein, colonies from samples 212 taken 24 h post-induction were white. This was readily shown to be due to overgrowth of the 213 population by plasmid-free bacteria (Fig. 1A). Consistent with these results, SDS-PAGE 214 analysis revealed a rapid burst of CheY::GFP synthesis immediately post-induction (Fig. 1B), 215 but little increase after a further 2 to $4 \mathrm{~h}$. Furthermore, about $80 \%$ of the CheY::GFP fusion 216 protein accumulated in inclusion bodies in the insoluble fraction (Fig. 1B), which was almost 217 non-fluorescent, indicating that GFP was incorrectly folded and therefore inactive.

218 Analysis of samples by flow cytometry revealed that the population pre-induction was 219 relatively homogenous but moderately fluorescent, reflecting the leakiness of the pET 220 promoter (Fig. 2A). Fluorescence had increased substantially within $3 \mathrm{~h}$ of IPTG addition. 
221 However, the small population of non-fluorescent bacteria already present in the culture 222 increased from $4 \%$ to $12 \%$ post-induction. After $25 \mathrm{~h}$, only a minority of the bacteria in the 223 culture were fluorescent due to overgrowth by unproductive, plasmid-free bacteria. Around $22420 \%$ of the population were permeable to propidium iodide, indicating loss of viability, 225 though these were split equally between fluorescent and non-fluorescent bacteria.

Optimisation of soluble CheY::GFP production by minimising post-induction growth228 arrest

229 Although the consequences of rapid over-expression of cloned genes are well documented, 230 less reported is the loss of colony forming units during recombinant protein production 231 (Sundström et al., 2004). We therefore investigated whether it was possible to optimise the 232 IPTG concentration not on the basis of quantity or speed of recombinant protein production, 233 but on the maximum level of fluorescence under conditions that greatly decreased the general 234 stress response. This involved growing the culture at the same temperature both before and 235 after induction to avoid any stress caused by a change in temperature; and the determination 236 of the concentration of the inducer, IPTG, that would allow maximum GFP fluorescence $24 \mathrm{~h}$ 237 post-induction. Based upon these criteria, optimal results were obtained with cultures grown 238 at $25^{\circ} \mathrm{C}$ and induced with $8 \mu \mathrm{M}$ IPTG, which had only a slight effect on exponential growth 239 and avoided selection of plasmid-free bacteria (Fig. 1C; D). Flow cytometry analysis showed 240 that fluorescence continued to increase for at least $25 \mathrm{~h}$ (Fig. 2B), and much greater 241 homogeneity in the culture: around $98 \%$ of bacteria were in the $\mathrm{GFP}^{+}$population both before 242 induction and after 3 and 25 hours post-induction; the number of nonviable, $\mathrm{PI}^{+}$bacteria at 25 $243 \mathrm{~h}$ was greatly reduced compared to the original protocol; and the $\mathrm{GFP}^{-}$population actually 244 decreased in size from $2 \%$ pre-induction to $0.7 \%$ after $25 \mathrm{~h}$ (Fig. 2B). Analysis of samples 245 from the culture by SDS-PAGE revealed that about $90 \%$ of the CheY::GFP had accumulated 
246 throughout the induction phase in the soluble protein fraction, in contrast to less than $20 \%$ 247 soluble product from the standard protocol (Fig. 1E). Furthermore, the yield of recombinant 248 protein was four-fold higher from the improved protocol than from the standard protocol due

249 to the production of a higher yield of biomass (Table 1). Finally it was demonstrated that 250 much higher yields of product could be generated following prolonged expression in fed251 batch cultures (Table 1).

\section{Molecular basis for the increased accumulation of CheY::GFP}

Aware of the stress on the bacterial host associated with the use of the BL21 / pET system,

strains were called C41 and C43, and it was subsequently shown that the basis for the 258

improved performance was a down-mutation of the promoter of the T7 polymerase gene

(Wagner et al., 2008). To determine whether the low concentration of IPTG coupled with the

261 hence explain why the improved protocol was successful, Western blots of samples from both

262 the standard and improved protocols were probed with anti-T7 RNA polymerase antibody

263 (Fig. 3). In contrast to the strong bands of cross-reacting antigen from the standard protocol,

264 so little T7 polymerase was produced using the improved protocol that it was not visible.

265 We then compared yields of CheY::GFP from strain BL21* using the improved 266 protocol with those from strains C41 and C43 generated using the standard protocol (Fig. 4).

267 The level of fluorescence (per unit volume) from the improved protocol was the same as that 268 from C41 and considerably higher than from C43 (not shown). The specific fluorescence (per 269 unit biomass) at the point of harvest was highest for BL21* using the improved protocol (Fig.

270 4A) and its cell density was only slightly lower than that for strain C41 (Fig. 4B). 
272 High-level production of a secreted recombinant $c$-type cytochrome using the improved 273 protocol

274 The model protein, CheY::GFP, is a soluble, cytoplasmic protein. It was therefore of interest 275 to determine whether the improved protocol for CheY::GFP production was sufficiently 276 generic to be exploited in the production of a secreted protein that requires extensive post277 translational modification and assembly in the bacterial periplasm. A Neisseria gonorrhoeae 278 gene of unknown function predicted to encode a $c$-type cytochrome, which we have 279 designated cytochrome $c_{2}$, was cloned into the expression plasmid, pET20bhc, and expressed 280 either using the standard protocol (induction with a high concentration of IPTG followed by a 281 decrease in growth temperature from $37^{\circ} \mathrm{C}$ to $25^{\circ} \mathrm{C}$ ) or the same optimised conditions that 282 were used for CheY::GFP. Under both sets of conditions, two bands of recombinant protein 283 were detected by SDS-PAGE stained for total protein: the upper band was pre-apocytochrome $284 c$ located in the cytoplasm; the lower band stained positively for covalently attached heme, 285 confirming that it was mature cytochrome located in the periplasm. Using the standard 286 protocol, cytochrome rapidly accumulated for a short time, but then production stopped as the 287 culture was overgrown by plasmid deficient bacteria (not shown). Even with the standard 288 protocol, some mature cytochrome was produced, but more than $95 \%$ of the product was pre289 apoprotein located in cytoplasmic inclusion bodies. In contrast, yields of mature cytochrome $290 c_{2}$ from the improved protocol were so high that the resulting E. coli culture was slightly 291 orange, and the cytochrome with covalently bound heme accumulated in the soluble, 292 periplasmic fraction of the bacteria (Fig. 5). This demonstrated that the improved protocol had 293 enabled post-translational secretion, periplasmic heme attachment and folding to keep pace 294 with the synthesis of the pre-apoprotein. Furthermore, analysis by SDS-PAGE revealed that 
295 only a small percentage of the pre-apoprotein had accumulated in the cytoplasmic fraction, or 296 been deposited into inclusion bodies (Fig. 5A).

\section{Accumulation of other recombinant proteins using the improved protocol}

299 The overproduction of two other recombinant proteins, namely the gonococcal cytochrome $c$ 300 peroxidase $(\mathrm{CCP} ; 47 \mathrm{kDa})$ from $N$. gonorrhoeae (Turner et al., 2003) and a non-E. coli 301 protein D-GFP (45 kDa) (Intellectual property; GSK) were produced using both approaches. 302 There was at least an 8-fold increase in the yields of mature CCP with covalently attached 303 heme and of soluble protein D-GFP when the modified approach was used compared with the 304 normal protocol, clearly reflecting the robustness of this approach for improving soluble 305 recombinant protein yields regardless of size, properties or bacterial host origin.

Discussion

308 The primary cause of failure to produce a correctly-folded recombinant protein in high yield 309 is well understood, namely the accumulation of incorrectly folded intermediates due to rates 310 of protein synthesis overwhelming post-translational modifications such as folding, secretion,

311 folding into membrane-spanning helices or the incorporation of prosthetic groups (reviewed 312 by Gasser et al., 2008). Different, and sometimes opposite, strategies depending on the 313 properties of the target protein are required to solve these problems (Gasser et al., 2008; 314 Hoffmann \& Rinas, 2004; Miroux \& Walker, 1996; Soriano et al., 2002; Wagner et al., 315 2008). Stress post-induction is especially severe when the IPTG-inducible T7 RNA 316 polymerase system in the E. coli BL21 host is used to accumulate high concentrations of 317 recombinant protein. Many genetic strategies have been described to decrease this stress 318 response (Miroux \& Walker, 1996; Soriano et al., 2002; Wagner et al., 2008), and a suite of 319 commercially available derivatives of BL21 and pET plasmids have been designed to 
320 overcome these problems. Consequently the Holy Grail of recombinant protein production,

321 the availability of generic protocols and hosts for the production of even the most difficult 322 target product, has yet to be achieved: recombinant protein production remains as much an art 323 as a science.

324 Although the consequences of rapid over-expression of cloned genes are well 325 documented, less reported is the loss of colony forming units during recombinant protein 326 production (Sundström et al., 2004). We therefore adopted a physiological approach to 327 investigate whether it was possible to optimise the IPTG concentration not on the basis of 328 quantity or speed of recombinant protein production, but on yield of GFP fluorescence under 329 conditions that greatly decreased the stress on the host. This involved growing the culture at 330 the same temperature both before and after induction to avoid any stress caused by a change 331 in temperature; and determination of the concentration of the inducer, IPTG, that would allow 332 optimal yields of GFP fluorescence $24 \mathrm{~h}$ post-induction. This approach defined conditions 333 that were suitable for the accumulation of two vastly different types of recombinant protein to 334 levels approaching $30 \%$ of the total protein content of the bacteria. Experiments currently in 335 progress are designed to determine whether this approach is applicable to other hosts and 336 expression systems, or limited to expression systems based upon the bacteriophage T7 337 polymerase that, due to the very high rates of transcription post-induction, impose an 338 excessive stress on the host bacterium (Soriano et al., 2002; Sørensen \& Mortensen, 2005). It 339 will be particularly interesting to know whether it can also be beneficial for other, less 340 stressful expression systems.

342 Acknowledgements

343 This work was funded by the UK Biotechnology and Biological Sciences Research Council 344 grant number BB/E005934/1 and a BBSRC CASE Research Studentship to SNA. The 
1

2

3345 FACSAria II cell sorter was funded by BBSRC Research Equipment Initiative grant 5

5

6

8

9

10

11

12

13

14

15

16

17

18

19

20

21

22

23

24

25

26

27

28

29

30

31

32

33

34

35

36

37

38

39

40

41

42

43

44

45

46

47

48

49

50

51

52

53

54

55

56

57

58

59

60

346 BBF0112371. We are grateful to Lesley Griffiths for excellent technical support. 


\section{References}

348 Chen Y, Song JM, Sui SF \& Wang DN (2003) DnaK and DnaJ facilitated the folding process 349 and reduced inclusion body formation of magnesium transporter CorA overexpressed in $350 \quad$ Escherichia coli. Prot Expr Purif 32: 221-231.

351 Dürrschmid K, Reischer H, Schmidt-Heck W, Hrebicek T, Guthke R, Rizzi A \& Bayer K 352 (2008) Monitoring of transcriptome and proteome profiles to investigate the cellular 353 response of $E$. coli towards recombinant protein expression under defined chemostat $354 \quad$ conditions. J Biotechnol 135: 34-44.

355 Gasser B, Saloheimo M, Rinas U, Dragosits M, Rodríguez-Carmona E, Baumann K, Guiliani 356 M, Parrilli E, Branduari P, Lang C, Porro D, Ferrer P, Tutino ML, Mattanovich D \& 357 Villaverde A (2008) Protein folding and conformational stress in microbial cells 358 producing recombinant proteins: a comparative host overview. Microb Cell Fact 7: 11.

359 Gill RT, Valdes JJ \& Bentley WE (2000) A comparative study of global stress gene 360 regulation in response to overexpression of recombinant proteins in Escherichia coli. $361 \quad$ Metabol Eng 2: 178-189.

362 Hewitt CJ, Nebe-von Caron G, Nienow AW \& McFarlane CM (1999) The use of multi363 stating flow cytometry to characterise the physiological state of Escherichia coli W3110 364 in high cell density fed-batch cultures. Biotechnol Bioeng 63: 705-711.

365 Hoffmann F \& Rinas U (2004) Stress induced by recombinant protein production in 366 Escherichia coli. Adv Biochem Eng Biotechnol 89: 73-92.

367 Hu XJ, O'Hara L, White S, Magner E, Kane M \& Wall JG (2007) Optimisation of production 368 of a domoic acid-binding scFv antibody fragment in Escherichia coli using molecular 369 chaperones and functional immobilisation on a mesoporous silicate support. Prot Expr $370 \quad$ Purif 52: $194-201$. 
371 Jones JJ (2007) Green fluorescent protein as an analytical tool to dissect the physiology of 372 recombinant protein production in fermenters. $\mathrm{PhD}$ thesis. University of Birmingham.

373 Jones JJ, Bridges AM, Fosberry AP, Gardner S, Lowers RR, Newby RR, James PJ, Hall RM 374 \& Jenkins O (2004) Potential of real-time measurement of GFP-fusion proteins. $J$ 375 Biotechnol 109: 201-211.

376 Lin B, Renshaw MW, Autote K, Smith LM, Calveley P, Bowdish K.S \& Frederickson S 377 (2008) A step-wise approach significantly enhances protein yield of a rationally-designed $378 \quad$ agonist antibody fragment in E. coli. Prot Expr Purif 59: 55-63.

379 de Marco A (2007) Protocol for preparing proteins with improved solubility by co-expressing $380 \quad$ with molecular chaperones in Escherichia coli. Nat Protoc 2: 2632-2639.

381 Miroux B \& Walker JE (1996) Over-production of proteins in Escherichia coli mutant hosts 382 that allow synthesis of some membrane proteins and globular proteins at high levels. $J$ 383 Mol Biol 260: 289-298.

384 Mitsuda M \& Iwasaki M (2006) Improvement in the expression of CYP2B6 by co-expression 385 with molecular chaperones GroES/EL in Escherichia coli. Prot Expr Purif 46: 401-405.

386 Nishihara K, Kanemori M, Kitagawa M, Yanagi H. \& Yura T (1998) Chaperone co387 expression plasmids: differential and synergistic roles of DnaK-DnaJ-GrpE and GroEL388 GroES in assisting folding of an allergen of Japanese cedar pollen, Cryj2, in Escherichia 389 coli. Appl Environ Microbiol 64: 1694-1699.

390 Rabhi-Essafi I, Sadok A, Khalaf N \& Fathallah DM (2007) A strategy for high-level 391 expression of soluble and functional human interferon alpha as a GST-fusion protein in $E$. 392 coli. Prot Eng Design Select 20: 201-209.

393 Sambrook J, Fritsch EF \& Maniatis T (1989). Molecular cloning: a laboratory manual. 2nd 394 edition. Cold Spring Harbor Press, Cold Spring Harbor, New York. 
395 Schrodel A, Volz J \& de Marco A (2005). Fusion tags and chaperone co-expression modulate 396 both the solubility and the inclusion body features of the recombinant CLIPB14 serine 397 protease. J Biotechnol 120: 2-10.

398 Sørensen HP \& Mortensen KK (2005) Advanced genetic strategies for recombinant protein 399 expression in Escherichia coli. J Biotechnol 115: 113-128.

400 Sundström H, Wållberg F, Ledung E, Norrman B, Hewitt CJ \& Enfors SO (2004) Segregation 401 to non-dividing cells in recombinant Escherichia coli fed-batch fermentation processes. 402 Biotechnol Lett 26: $1533-1539$.

403 Soriano E, Borth N, Katinger H \& Mattanovich D (2002) Optimization of recombinant 404 protein expression level in Escherichia coli by flow cytometry and cell sorting. Biotech 405 Bioeng 80: 93-99.

406 Thomas PE, Ryan D, \& Ledwin W (1976) An improved staining procedure for the detection 407 of peroxidase activity of cytochrome P-450 on sodium dodecyl sulphate polyacrylamide $408 \quad$ gels. Anal Biochem 75: 168-176.

409 Turner S, Reid E, Smith H \& Cole JA (2003) A novel cytochrome $c$ peroxidase from $410 \quad$ Neisseria gonorrhoeae: a lipoprotein from a Gram-negative bacterium. Biochem J 373: $411 \quad 865-873$.

412 Vera A, Gonzalez-Montalban N, Aris A \& Villaverde A (2007) The conformational quality of 413 insoluble recombinant proteins is enhanced at low growth temperatures. Biotechnol $414 \quad$ Bioeng 96: 1101-1106.

415 Villaverde A \& Carrio MM (2003) Protein aggregation in recombinant bacteria: biological 416 role of inclusion bodies. Biotechnol Lett 25: 1385-1395.

417 Waldo GS, Standish BM, Berendzen J \& Terwilliger TC (1999) Rapid protein-folding assay $418 \quad$ using green fluorescent protein. Nat Biotechnol 17: 691-695. 
1 4

5

7

8

9

11

12

13

14

15

16

17

18

19

20

21

22

23

24

25

26

27

28

29

30

31

32

33

34

35

36

37

38

39

40

41

42

43

44

45

46

47

48

49

50

51

52

53

54

55

56

57

58

59

60

419 Wagner S, Klepsch MM, Schlegel S, Appel A, Draheim R, Tarry M, Högbom M, van Wijk

420 KJ, Slotboom DJ, Persson JO \& de Gier, J-W (2008) Tuning Escherichia coli for 421 membrane protein overexpression. PNAS 105: 14371-14376. 


\begin{tabular}{|c|c|c|c|c|c|c|}
\hline Protocol & Format & $\begin{array}{l}\text { Biomass, } \\
\text { g dry mass } \\
L^{-1 \S}\end{array}$ & $\begin{array}{l}\text { Percentage } \\
\text { recombinant } \\
\text { protein, } \%^{\dagger}\end{array}$ & $\begin{array}{l}\text { Yield of } \\
\text { recombinant } \\
\text { protein, } \\
g L^{-1 \ddagger}\end{array}$ & $\begin{array}{l}\text { Specific } \\
\text { fluorescence, } \\
\text { Fluorescence } \\
\text { units } / O D_{650}\end{array}$ & $\begin{array}{l}\text { Total } \\
\text { fluorescence, } \\
\text { units }\end{array}$ \\
\hline \multirow[t]{2}{*}{ Standard } & $\begin{array}{l}\text { Shake } \\
\text { flask }\end{array}$ & 2.3 & 21 & 0.34 & 60.8 & 350 \\
\hline & $\begin{array}{l}\text { Batch } \\
\text { fermenter }\end{array}$ & 2.4 & 25 & 0.42 & 106.0 & 627 \\
\hline \multirow[t]{3}{*}{ Improved } & $\begin{array}{l}\text { Shake } \\
\text { flask }\end{array}$ & 6.16 & 52 & 2.24 & 214.0 & 3240 \\
\hline & $\begin{array}{l}\text { Batch } \\
\text { fermenter }\end{array}$ & 6.6 & 29 & 1.34 & 269.4 & 4440 \\
\hline & $\begin{array}{l}\text { Fed- } \\
\text { batch } \\
\text { fermenter }\end{array}$ & 26.6 & 31 & 5.8 & 289.2 & 19200 \\
\hline
\end{tabular}

\section{4}

$425{ }^{\S}$ Biomass was calculated on the assumption that a culture with an $\mathrm{OD}_{650}$ of 1.0 contains $0.4 \mathrm{~g}$

426 dry mass $\mathrm{L}^{-1}$

427 The percentage of recombinant protein was estimated from SDS-PAGE gels by densitometry

$428{ }^{\ddagger}$ Recombinant protein yield was estimated based on the assumption that $70 \%$ of the bacterial

429 culture dry mass is protein. 


\section{$430 \quad$ Figure legends}

432 Fig. 1. Optical density, colony forming units, plasmid retention and SDS-PAGE profile for 433 the standard (A, B) and improved (C, D, E) protocols. IPTG was added at time zero. The 434 arrow beside the gels indicates the position of the $42 \mathrm{kDa}$ CheY::GFP protein. BI: before 435 induction; S: soluble fraction; I: insoluble fraction; M: marker proteins.

436

437 Fig. 2. Flow cytometry analysis of before, $3 \mathrm{~h}$ after and $25 \mathrm{~h}$ after IPTG induction for the 438 standard (A) and improved (B) protocols. Note that only the final $25 \mathrm{~h}$ samples were stained 439 with propidium iodide (PI). X axes show PI-emitted fluorescence measured at $\sim 630 \mathrm{~nm}$ and Y 440 axes show GFP-emitted fluorescence measured at $\sim 510 \mathrm{~nm}$. The numbers in each quadrant 441 show percentage of bacteria in each sub-group.

443 Fig. 3. Western blot to detect T7 RNA polymerase during CheY::GFP accumulation using the 444 standard (A) and improved (B) protocols. BI: before induction; other time points are post445 induction.

Fig. 4. Comparison of CheY::GFP accumulation during expression using the improved and 448 standard protocols and E. coli BL21* as the host and in strains C41 and C43 using the Miroux 449 and Walker (1996) protocol. A. Specific fluorescence 3, 7 and 24 h post-induction. B. Growth 450 post-induction, plotted on linear scale to show differences between strains and protocols more 451 clearly. IPTG was added at time zero.

453 Fig. 5. Production of gonococcal cytochrome $c_{2}$ using the improved protocol. The SDS454 PAGE gels show yields of total protein (A. Coomassie stained gel) and of mature cytochrome 
$455 c_{2}$ (B. Gel stained for heme-dependent peroxidase activity). The upper arrow indicates the 456 position of the pre-apo-cytochrome located in the cytoplasm; the lower arrow is the mature 457 cytochrome with heme attached post-secretion into the periplasm. 


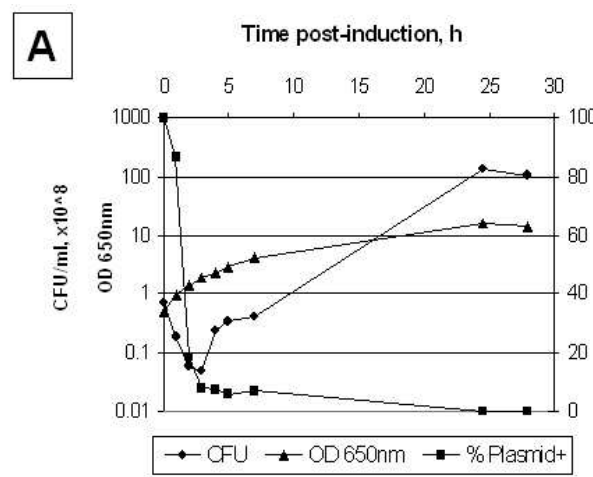

C

B
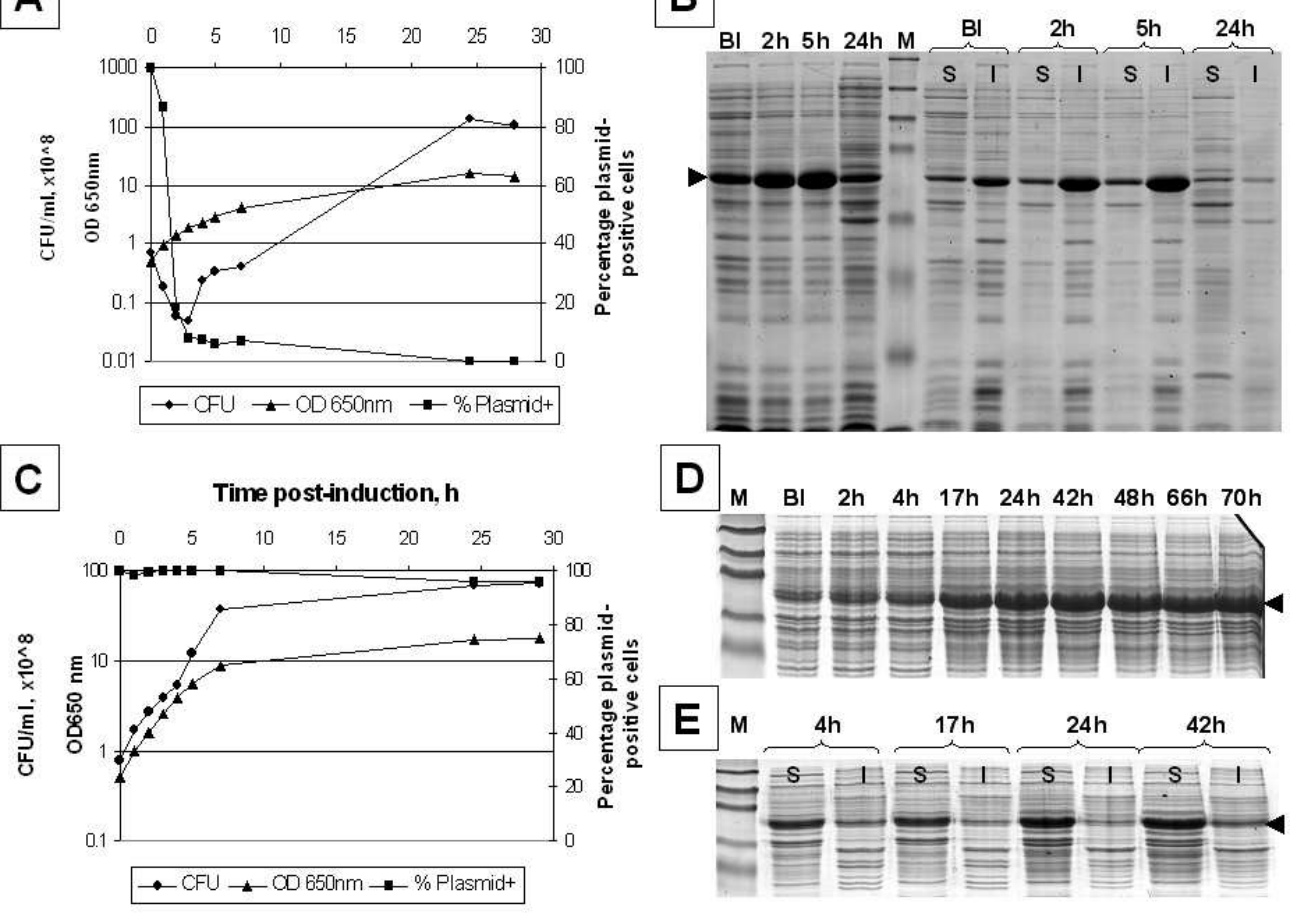

D $M \quad B I \quad 2 h \quad 4 h \quad 17 h \quad 24 h \quad 42 h \quad 48 h \quad 66 h \quad 70 h$ - $\equiv$

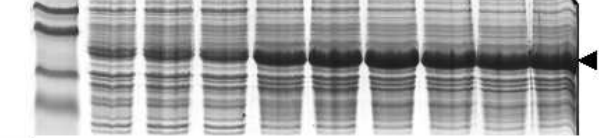
E $M \overbrace{s}^{4 \mathrm{~h}} \overbrace{}^{17 \mathrm{~h}} \overbrace{}^{24 \mathrm{~h}} \underbrace{42 \mathrm{~h}}$

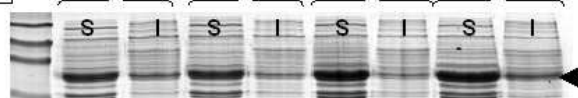

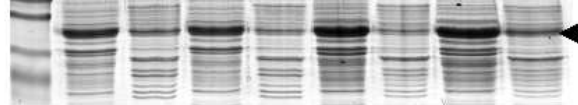



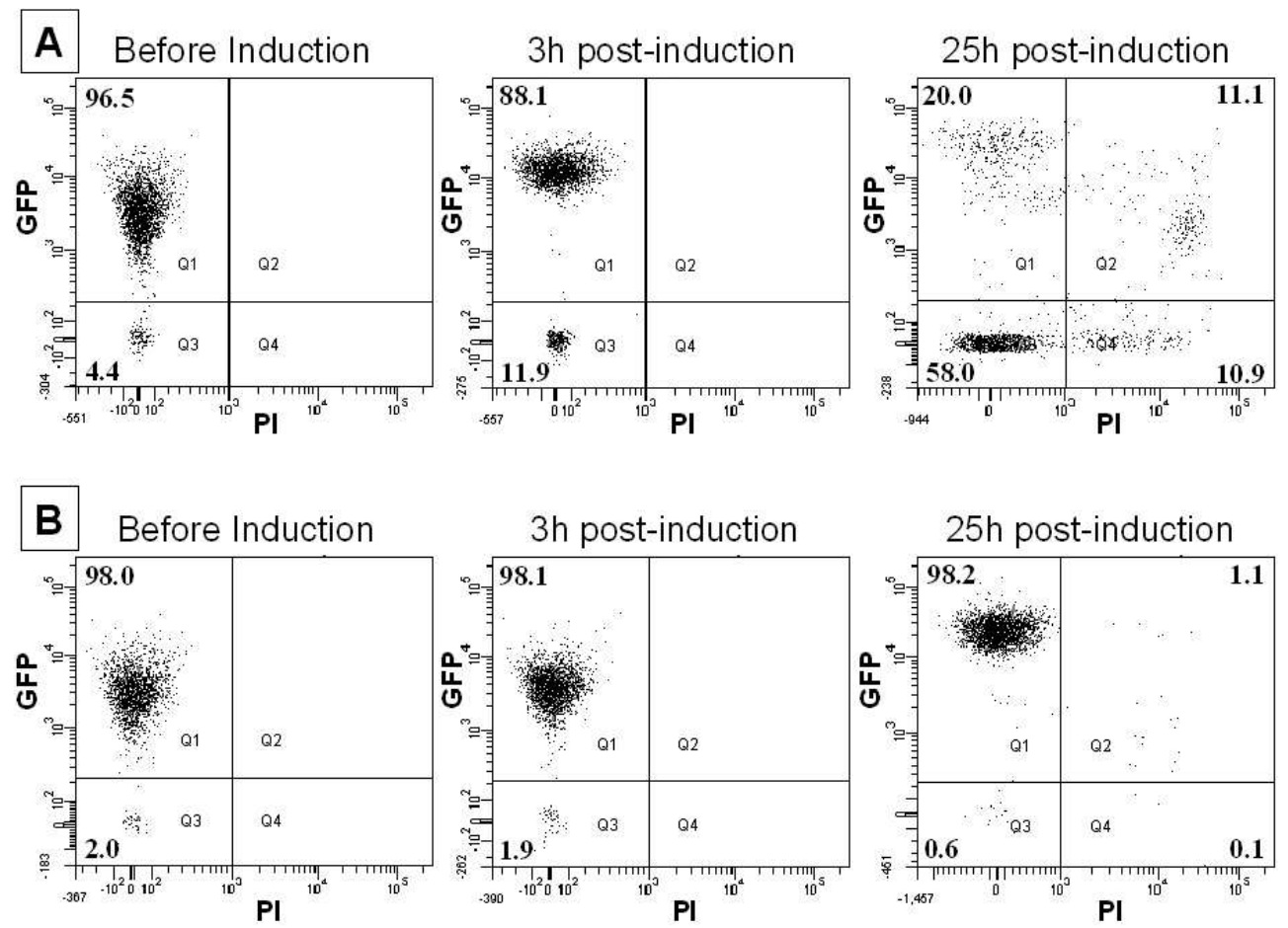

31

32

33

34

35

36

37

38

39

40

41

42

43

44

45

46

47

48

49

50

51

52

53

54

55

56

57

58

59

60 


1
2
3
4
5
6
7
8
9
10
11
12
13
14
15
16
17
18
19
20
21
22
23
24
25
26
27
28
29
30
31
32
33
34
35
36
37
38
39
40
41
42
43
44
59
45
46
47
48
49
50
51
52
54
56

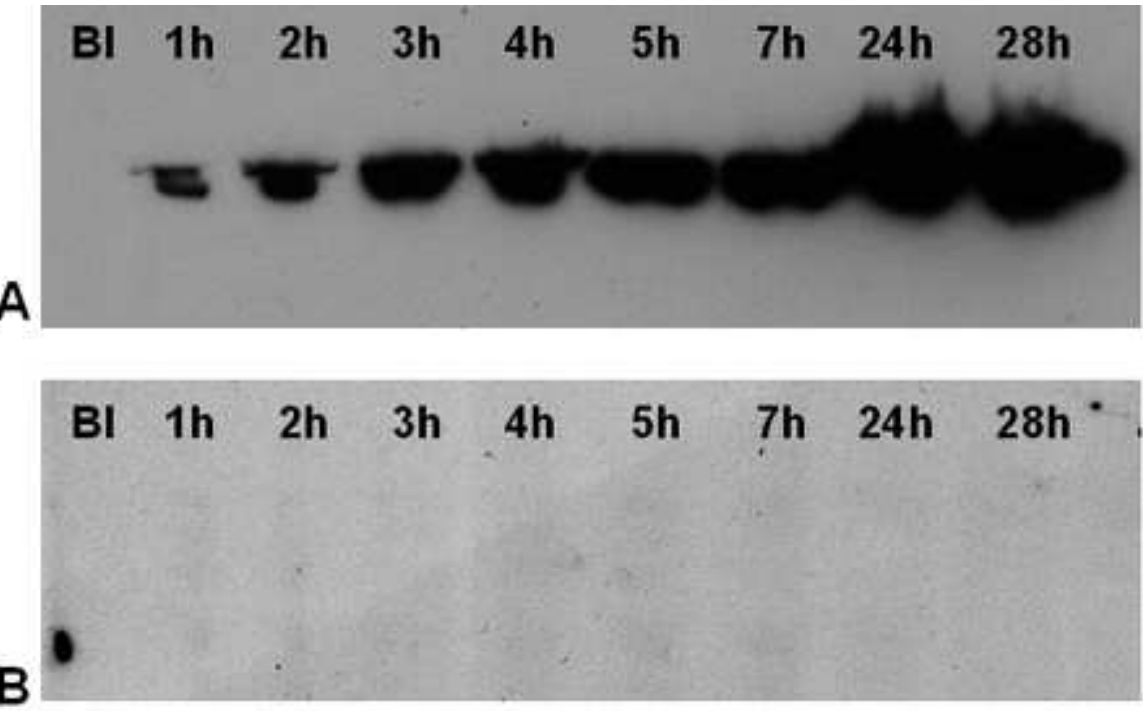



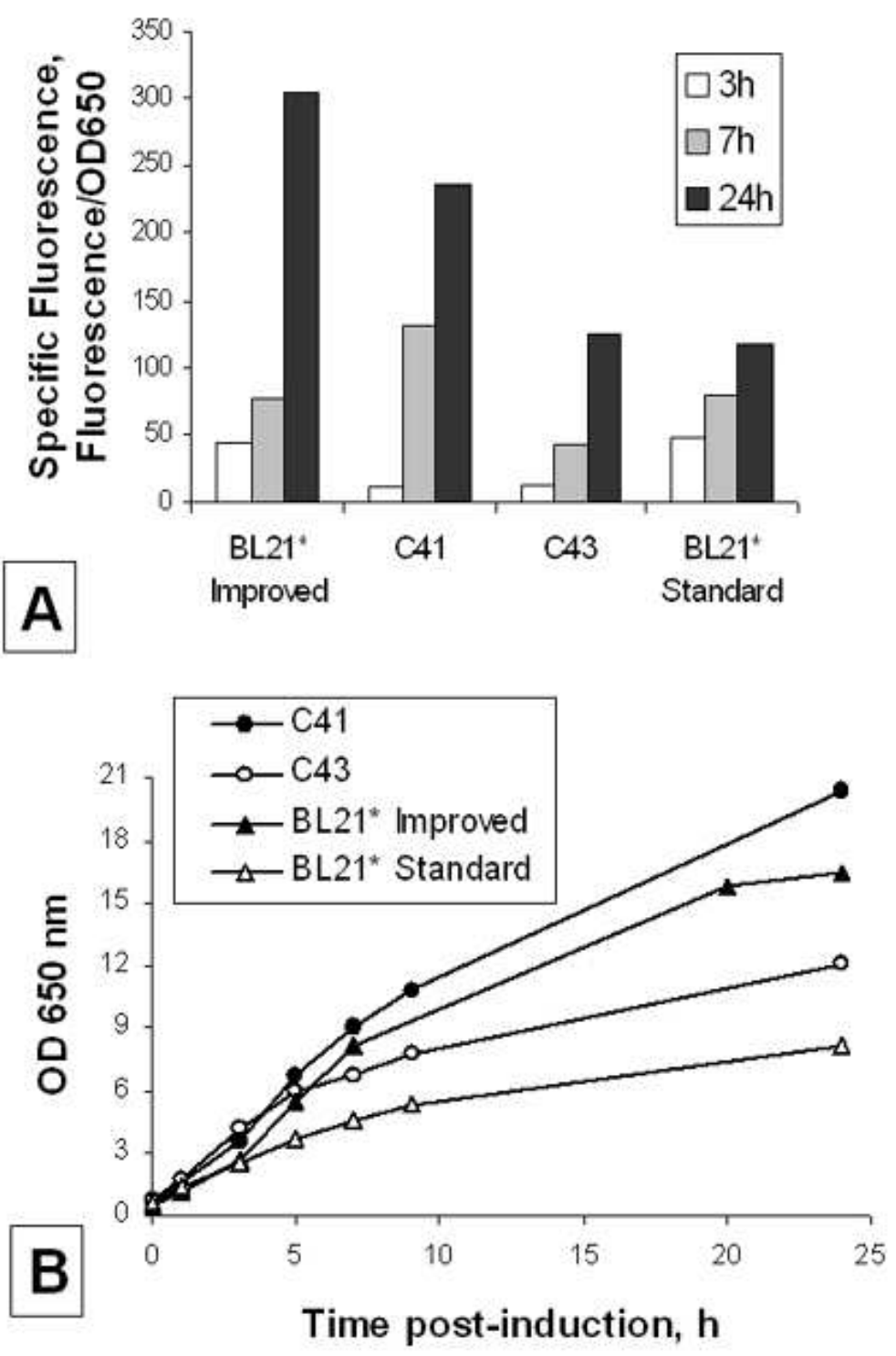


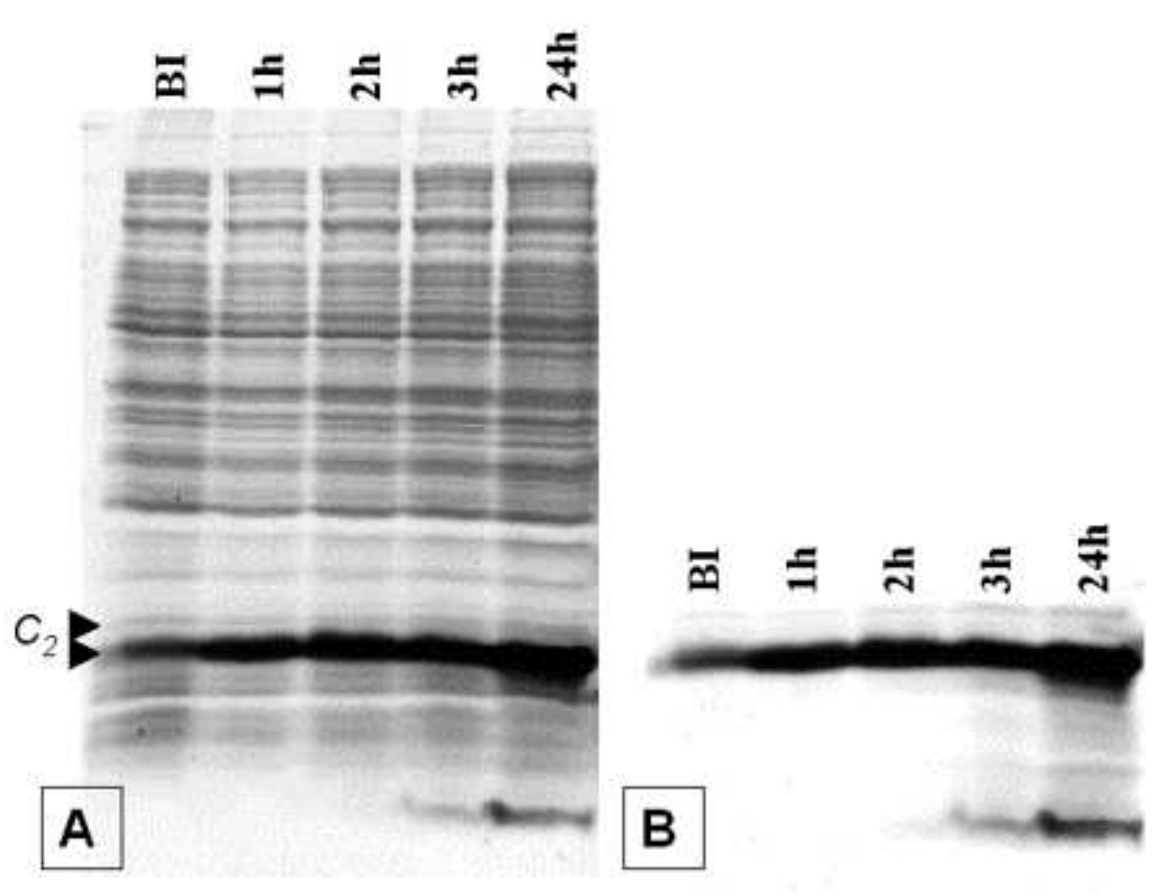

1

2

3

4

5

6
7

8

9

10

11

12
13

14

15

16

17

18

19

20

21

22

23

24

25

26

27

28

29

30

31

32

33

34

35

36

37

38

39

40

41

42

43

44

45

46

47

48

49

50

51

52

53

54

55

56

57

58

59

60 